\title{
Barriers Perceived by Teachers at Work, Coping Strategies, Self-efficacy and Burnout
}

\author{
Fernando Doménech Betoret ${ }^{1}$ and Amparo Gómez Artiga ${ }^{2}$ \\ ${ }^{1}$ Universitat Jaume I (Spain) \\ ${ }^{2}$ Universitat de València (Spain)
}

This study examines the relationships among stressors, coping strategies, self-efficacy and burnout in a sample of 724 Spanish primary and secondary teachers. We understood stressors as barriers perceived by teachers that interfere with their work meeting learning objectives and which cause them stress and burnout. An analysis of teacher responses using hierarchical regression revealed that pedagogical barriers had significant positive effects on the burnout dimensions. Furthermore, the results show not only the moderator role played by coping strategies in the pedagogical barriersburnout dimensions relationship, but also the association between self-efficacy and the coping strategies used by teachers. Practical implications are discussed.

Keywords: stressors, self-efficacy, coping strategies, teaching burnout.

\begin{abstract}
Este estudio examina las relaciones existentes entre estresores, modos de afrontamiento, autoeficacia y síndrome de quemado en una muestra de 724 profesores españoles de primaria y secundaria. Los potenciales estresores se entendieron como factores barreras que interfieren la labor del profesorado causándoles burnout. Los resultados obtenidos a través de las regresiones múltiples jerárquicas realizadas revelaron que las barreras pedagógicas percibidas por el profesorado predicen significativamente las tres dimensiones del burnout (una vez controladas las variables demográficas). También revelaron el papel modulador que juegan las estrategias de afrontamiento en la relación barreras pedagógicas-burnout, así como la relación entre autoeficacia, en gestión e instrucción, y el tipo de estrategias de afrontamiento utilizadas por el profesorado. Finalmente, se analizan las implicaciones educativas derivadas de estos hallazgos.

Palabras clave: estresores, barreras pedagógicas, autoeficacia, estrategias de afrontamiento, burnout docente.
\end{abstract}

This research has been possible thanks to grant GV05/054 provided by The Generalitat Valenciana.

Correspondence concerning this article should be addressed to Fernando Doménech Betoret. Departamento de Psicología Evolutiva y de la Educación. Universidad Jaume I. Castellón. (Spain). Phone: +34-964729550. Fax: +34-964729262. E-mail: betoret@psi.uji.es 
Accomplishing learning objectives gives teaching activities meaning. Unlike other jobs or services in which the supplier does something for customers, the supplier in the field of education does something to customers, that is, students (Harvey \& Green, 1993). It is, therefore, the participant's transformation process that becomes explicit and operationalised through learning objectives. Establishing learning objectives may be considered the first step of the whole teaching process whose purpose is to determine the results that students are expected to obtain through a teaching/learning process conducted in the classroom. Besides, these objectives provide the means to carry out effective teaching as they serve as guides for teachers, allowing them to devise and develop the didactic strategies and resources required to provide teaching (Heinrich, Molenda, Russell, \& Smaldino, 1996). In a formal educational situation, effective teaching comes about when students' performance changes in accordance with the learning objectives set out. Nonetheless, the teachers' teaching process may be affected by a considerable number of obstacles, or barriers, which diminish the effectiveness of their teaching by hindering them from fully meeting the learning objectives established and causing them burnout (Blase, 1982; Harrison,1983; Pines, 1993; Salanova, Cifre, Grau, Llorens, \& Martínez, 2005).

The burnout phenomenon among teachers is receiving increasing attention by researchers in many countries, including Spain, as the many works which have been published in Spain in recent years reflect (Calvete \& Villa, 1999; Doménech-Betoret, 2006, 2009; Durán, Extremera, Montalbán, \& Rey, 2005; Flores \& Fernandez-Castro, 2004; Salanova, Martínez, \& Lorente, 2005). However, some important limitations remain despite the large number of studies conducted and the significant progress made in this field. One limitation is the difficulty to compare the results obtained owing to the various ways of conceptualising burnout and the diverse instruments used to measure it. Nonetheless, there seems to be growing evidence of a quite generalised consensus to consider burnout as a threedimensional construct by adopting the proposals of Maslach and Jackson (1986), and Maslach, Jackson and Leiter (1996). According to these authors, the first and main aspect of burnout is emotional exhaustion, which is characterised by feelings of being emotionally and mentally exhausted. The second symptom is depersonalisation, which involves adopting a cynical and negative attitude towards students. Finally, the third symptom is known as low personal accomplishment, characterised by feeling poorly efficient and less competent at work. To measure these three dimensions, Maslach and Jackson devised the Maslach Burnout Inventory (MBI), which we had used in this work.

This study examined the relationship among pedagogical barriers, ways of coping, self-efficacy and burnout in a sample of primary and secondary school Spanish teachers. These variables apparently play an important role in the explanation and comprehension of the burnout phenomenon, which is why they have been considered, although separately, in the most important general theoretical models to explain the burnout syndrome (see the review by Gil-Monte \& Peiró 1999). If considered simultaneously, they could provide not only new data to account for burnout, but could also create bridges between the different theoretical models.

Pedagogical barriers and burnout. The importance of barrier factors in developing burnout has been highlighted by a number of general and specific theoretical models. Among the general theoretical models we find those proposed by Harrison (1983) and Pines (1993). According to Harrison (1983), when workers have many barrier factors and few help factors in their working environment, their feelings of effectiveness decrease because they are not able to accomplish their objectives completely. When this situation extends over time, burnout emerges. Pines (1993) took Harrison's model (1983) as a starting point and designed a similar model, but one with motivational variables. Barrier factors have also been considered relevant in other specific theoretical models, such as that proposed by Blase (1982), or the model proposed by DoménechBetoret (2009) derived from the previous one. In his socialpsychological model of teacher stress and burnout, Blase reported that the barriers interfering with the instructional process not only make it difficult to accomplish learning objectives, but also cause teachers stress and burnout. Authors like Salanova, Cifre, Grau, Llorens and Martínez (2005) described this scenario in a similar way when they argued that "organisational obstacles are occupational environmental factors capable of restricting performance which require extra (physical or psychological) effort to be made by people, and are associated with certain physical or psychological costs" (p. 163).

With their research works into stress and burnout, several authors have generally attempted to identify the variables causing stress by asking teachers to make a list of the variables that cause them stress (see, for example, Manthei, Gilmore, Tuck, \& Adair, 1996; Pithers \& Fogarty, 1995; Pithers \& Soden, 1998). Nonetheless, this process has three major limitations. Firstly, stress is a difficult abstract construct to define and may lead to different subjective interpretations of each subject. Secondly, these questionnaires are limited as they present a list of potential stressors with no coherent theoretical structure. Thirdly, they provide no additional information to explain the reasons why these stressors cause stress among teachers, which makes the design of efficient intervention programmes difficult. In an attempt to overcome these limitations, this study has redefined the stressor concept from a more operative and educational viewpoint based on the Psychological-Social Model proposed by Blase (1982). This model defines stressors as work-related variables which tend to interfere with the efforts teachers make while 
conducting their profession, that also make it difficult for them to accomplish the learning objectives established (demands), and which then cause them stress and burnout (Blase, 1982). With this approach, and as an attempt to overcome the aforementioned limitations, we devised a questionnaire with potential stressors, understood as pedagogical barriers, to conduct this research. The system structure of this instrument is based on previous proposals to consider the scholarly contexts affecting teachers' work to a lesser or greater extent. These contexts have been ordered from the closest or most micro-systemic contexts (the classroom, for example) to the most distant or macrosystemic ones (Administration, for instance) (Kelchtermans, 1999; Lens \& Neves de Jesus, 1999; Woods, 1999).

Finally, it is necessary to point out that these pedagogical barriers (stressors) are not static variables, but dynamic ones which change in terms of space and time. In light of this, the present work considers the changes which have taken place in Spain in recent years and which may have contributed to increase stress among teachers. Among these changes we find the emigration phenomenon which has led to classrooms becoming multiracial and multicultural, and the changing legislation frequently introduced into the Spanish education system (LODE, 1985; LOGSE, 1990; LOCE, 2002; LOE, 2006).

By taking into account such considerations, the first objective of this study is to determine to what extent these pedagogical barriers are capable of predicting and explaining teacher burnout.

Pedagogical barriers, coping strategies and burnout. Previous research has proved that the impact of stressors (pedagogical barriers in this study) on the subject depends, to a great extent, on the coping strategies used (Jex, Bliese, Buzzel, \& Primeau, 2001). The authors have attempted to identify the various kinds of coping strategies that people use to cope with threatening or stressful situations. One of the most well-known classifications is that of Folkman and Lazarus $(1980,1985)$. These authors distinguish between problem-solving strategies which aim to neutralise the problem, and emotion-focused coping strategies that aim to cushion the subject's emotional impact. Although both response types are used in many cases, problem-solving strategies tend to predominate when the subject perceives they may help solve or cushion the problem, whereas emotion-focused coping strategies usually predominate when the subject perceives that the stressor will last and has to be faced in the best possible way (Folkman \& Lazarus, 1980). Later, other categories emerged as the result of subsequent research works. One example is the classification of Endler and Parker (1990) which extends and completes the former classification by proposing a third category known as avoidance strategies. In this context, one question that researchers have considered is whether some strategies are more efficient for coping with stressful situations than others. Along these lines, some studies (Endler \& Parker, 1990) have emphasised problem- solving strategies and the search for social support as they have proved relevant to help subjects adapt emotionally, and have also provided better results. Conversely however, avoidance strategies have had negative results for those people who use them. By applying these considerations to our study, it seems logical to believe that the teachers who use the active coping strategies (problem-solving strategies in educational practice) actually fulfil the learning objectives established in their subject matter(s) to a greater extent, thus obtaining better results. Consequently, and according to Blase's approaches (1982), these teachers will also feel more satisfied at work and will suffer less burnout, and vice versa. Based on this rationale, the second objective of the study is to examine the modulator role played by coping strategies (actives and passives) between pedagogical barriers and teacher burnout.

Self-efficacy and coping strategies. Self-efficacy is a component of Bandura's Social Cognitive Theory (SCT) (1986) and is defined as "an individual's belief in his or her own ability to organize and implement action to produce the desired achievements and results" (Bandura, 1997, p. $3)$. A number of studies has demonstrated the effect of the mitigating or reducing role of efficacy on teachers' stress and burnout (Brouwers, 2000; Brouwers, Evers, \& Tomic, 2001; Chan, 1998, 2002; Dick, \& Wagner, 2001; DoménechBetoret, 2005, 2006, 2008; Friedman, 2003). The idea is that when teachers positively self-assess this construct, they tend to suffer less stress and burnout than the teachers who negatively self-assess it. Similarly, other research works have shown that burnout may come about through "a selfefficacy crisis" (Chernis, 2003, Llorens, García-Renedo, \& Salanova, 2005). Yet self-efficacy may also affect the barrierburnout relationship indirectly through coping strategies (Leiter, 1991) since self-efficacy beliefs can influence the type of coping strategies used to neutralize or overcome the barriers or obstacles interfering with teachers' performance (Tesluk \& Mathieu, 1999). Recent studies (Salanova, Grau \& Martínez, 2005) have shown that the relationship between self-efficacy and coping strategies used self-efficacy beliefs and coping strategies. These authors consider self-efficacy a powerful organisational facilitator that allows to develop actions and effective strategies (active coping strategies) to overcome or mitigate the problems caused by the pedagogic barriers interfering with teachers' performance (Salanova, Cifre, Grau, Llorens, \& Martínez, 2005). Therefore, these research works support the idea that the self-efficacy beliefs perceived by subjects can help explain why teachers use a specific type of strategy to face the obstacles that interfere with their pedagogic practice, thus preventing them from reaching their learning objectives. Based on this rationale, it is interesting to examine the relationship between selfefficacy and the coping adopted strategy in the barrier factors context.

By taking into account that the more influential selfefficacy beliefs are, the better they adapt to a specific 
context (Bandura 1997; Salanova, Peiró, \& Schaufeli, 2002), for this study we considered teacher-perceived selfefficacy to teach (teaching self-efficacy) and perceived self-efficacy to deal with discipline and conflicts among students (management self-efficacy). These two forms of self-efficacy complement each other and are needed to fulfil learning objectives. Thus, we believe it important to use them. Whereas teaching efficacy focuses more on the teachers' educating role and has been mentioned in numerous works (Chan, 2002; Flores, \& Fernández-Castro, 2004; Salanova, Cifre, Grau, Llorens, \& Martínez, 2005), classroom management self-efficacy has been the object of few studies.

Based on these considerations, the third objective of this research is to examine the relationship between self-efficacy (teaching and management) and the coping strategies used by teachers.

Objectives and hypotheses. Based on the aforementioned considerations, the objectives of this work are posited below.

Firstly, to examine the predictive capacity of pedagogical barriers in teacher burnout. We hypothesise that pedagogical barriers will positively predict teacher burnout. Secondly, to examine the modulator role of coping strategies in the relationship between pedagogical barriers and burnout. We hypothesise that coping strategies (active and passive) will play a modulator role between pedagogic barriers and burnout. The interaction between pedagogical barriers and active coping strategies will reduce the possibility of burnout, whereas the interaction between pedagogical barriers and passive coping strategies will increase it. Thirdly and finally, to examine the relationship among self-efficacy (teaching and management) and the coping strategies used by teachers to overcome or to neutralise pedagogical barriers. We hypothesise a positive and significant association between self-efficacy and active coping strategies, and a negative and significant association between self-efficacy and passive coping strategies.

\section{Method}

\section{Participants}

In this study, a total of 724 Spanish teachers participated (271 men, 37.4\%, and 453 women, 62.6\%) of primary $(N=317,43.8 \%)$ and secondary $(N=407,56.2 \%)$ schools. The schools were state $(n=508,70.2 \%)$, subsidised private $(n=179,24.7 \%)$, and private $(n=37,5.1 \%)$. They were located in rural $(n=55,7.6 \%)$ and urban $(n=669,92.4 \%)$ areas in the province of Castellón (East Spain). Participants' ages ranged between 20 and 65 years as follows: $16.4 \%$ $(n=119)$ of the sample were in the 20-29 age group, 31.2\% $(n=226)$ were $30-39$ years old, $34.9 \%(n=253)$ were aged $40-50$ years, and $17.4 \%(n=126)$ were older than 50 years (see Table 1 for the descriptive statistics).
Table 1

The participants' characteristics (total $N=724$ )

\begin{tabular}{lcc}
\hline Categories & Frequences & Percentages \\
\hline Gender & & \\
$\quad$ Males & 271 & $37.4 \%$ \\
Females & 453 & $62.6 \%$ \\
Age & & \\
20-29 years old & 119 & $16.4 \%$ \\
30-39 years old & 226 & $31.2 \%$ \\
40-49 years old & 253 & $34.9 \%$ \\
over 50 years old & 126 & $17.4 \%$ \\
Level & & \\
Primary education & 317 & $43.8 \%$ \\
$\quad$ Secondary education & 407 & $56.2 \%$ \\
Type of school: & & \\
Public & 508 & $70.2 \%$ \\
Subsidised private & 179 & $24.7 \%$ \\
Private & 37 & $5.1 \%$ \\
Location & & \\
$\quad$ Rural & 55 & $7.6 \%$ \\
Urban & 669 & $92.4 \%$ \\
\hline
\end{tabular}

\section{Procedure}

The questionnaires were supplied to the teachers of the different schools in accordance with four parameters: level of education taught (primary, secondary), type of schools (state, subsidised public, private), location (rural, urban) and school size (small, medium, large). After selecting the schools, a presentation letter was sent by post requesting its collaboration and informing the school of the research work. A few days after posting the letter, we requested an interview with the school headmaster/mistress by telephone. Having agreed on an interview date, two collaborators (scholarship holders) travelled to the schools to provide verbal information about the research work, to clarify any doubts and to ask for permission to interview the teaching staff. A battery of questions in an envelope was handed to those teachers willing to participate so that the teachers could answer them anonymously. The collaborators explained how they should be completed and a form of contact was established in case the teachers had any doubts while answering the questions. Finally, a collection date was agreed on with the teachers. Of all the teachers interviewed, $60 \%$ completed the questionnaires.

\section{Measuring instruments}

Multicontext stressors scale (31 items). This questionnaire is a revised version of that used by Doménech-Betoret (2006) which considers the changes that have taken place in Spain recently in terms of the emigration phenomenon and legislation on education. It 
has been devised from a systemic school context viewpoint, distinguishes among the class, school and national (administration) levels, and takes previous studies as a reference (Kelchtermans, 1999; Lens \& Neves de Jesus, 1999; Woods, 1999). The teachers were asked the following: "Indicate to what extent the elements or conditions listed below make it difficult to fulfil the learning objectives with students". The teachers answered on a 4-point Likert scale: (0) they do not interfere with me in the least, (1) they interfere with me to some extent, (2) they interfere with me quite a lot, (3) they interfere with me a great deal. Four items were eliminated with a preliminary factorial analysis to make the interpretation quite clear as they had significant loads (load above .30) on more than one factor. Then a second exploratory factorial analysis was carried out with the 31 remaining items using the principal components analysis (PCA) method and oblimin rotation given the correlations observed among the factors in previous studies (DoménechBetoret, 2006). Six factors with good internal consistency indices were extracted (ranging between .81 and .93, and an overall Cronbach's $\alpha$ of .92) and explained $70.86 \%$ of the variance (see Table 2 for further details). A confirmatory factorial analysis was conducted afterwards with the EQS programme (Bentler, 1995, 2006) and revealed good adjustment indices (Chi-Square $\chi^{2}=868.290 ;$ D.F. $=358$; $N F I=.94 ; N N F I=.96 ; C F I=.96 ; G F I=.92 ; A G F I=.89$; $R M S E A=.045)$ when there were covariances between the errors of the items belonging to the same factor or among factors. For this study, the average total score of the six factors obtained was calculated; high scores reflected a major interference of the obstacles while attempting to fulfil the learning objectives, and low scores indicated less interference while attempting to fulfil the learning objectives. The complete scale is found in the Annexe.

Coping strategies scale (7 items). This scale has been especially devised for this study, and is based on the works of Folkman and Lazarus, 1980, 1985, and that of Endler and Parker, 1990. Teachers were asked the following question: "How often do you act when your work conditions make it difficult to fulfil the learning objectives with students?" To answer this question, the teachers assessed a list of possible actions using a 4-point Likert-type scale: Rarely or never (0), Sometimes (1), Frequently (2), Always or almost always (3). An explanatory factorial analysis was applied to the set of scale items using the PCA method with varimax rotation. Two factors were extracted and explained $61.42 \%$ of the variance. The first factor was made up of 4 items (with a Cronbach's $\alpha$ of .67) corresponding to passive coping or avoidance strategies. The items which made up the first factor were: "I give up, I can't do anything else", "I escape among my hobbies", "I avoid the situation as best as possible" and "I resort to distraction to sidestep things". The second factor comprised three items (with a Cronbach's $\alpha$ of .70) corresponding to active coping strategies or problem-solving strategies. The items forming this second factor were the following: "I try to make more effort", "I try to find solutions" and "I try to improve the next time". For further details, see Table 2.

Teacher self-efficacy (10 items). Teacher self-efficacy perceived by the teacher was measured with a version of the scale designed by Schwarzer, Schmitz and Daytner (1999) (see: http:www.ralfschwarzer.de). This scale evaluated the teacher's confidence in his or her ability to efficiently carry out a teaching process. Some examples of the items in this scale were: "I'm convinced I am capable of successfully teaching any content related to my speciality, even to the most difficult students", "I am confident my teaching skills respond to my students' needs, even on a bad day". The teachers answers scored on a 4-point Likert-type scale with answer options ranging from 1 (I totally disagree) and 4 (I totally agree). The internal consistency obtained through Cronbach's alpha test was .84. A general measure of teacher self-efficacy was obtained by calculating the average of the scores obtained in the items that the scale comprised in such a way that the higher the score, the greater the selfefficacy perceived; and the lower the score, the lesser the self-efficacy perceived. Details are provided in Table 2.

Classroom management self-efficacy (4 items). Selfefficacy perceived by the teacher to play the classroom management role was measured with a reduced version of the original scale of Doménech-Betoret (2006). In order to examine its factorial structure, a PCA was done with varimax rotation. A single factor was obtained which explained $72.57 \%$ of the total variance. All the items were over .50 . The internal consistency obtained by Cronbach's alpha test was .87. The teachers' answers scored on a 4-point Likerttype scale whose answer options ranged from 1 (I totally disagree) to 4 (I totally agree). A general measurement of management self-efficacy was obtained by calculating the average of the scores obtained with the four items making up the scale in such a way that the higher the score obtained, the greater the management self-efficacy perceived; and the lower the score obtained, the lesser the management self-efficacy perceived. The items which made up this scale were as follows: "I know how to act efficiently in the face of any conflict (aggressions, insults, mistreatments, etc.) which may arise among my students", "I know how to efficiently neutralise any disruptive or unacceptable conduct I see among the students in my class", "I am capable of maintaining order and discipline in my classes, even with difficult groups", "I know how to act to create an atmosphere of respect and a peaceful atmosphere with all the students together, even with the difficult groups". See Table 2 for further details.

The teacher burnout scale (22 items). Teacher burnout was measured using a Spanish version of the original scale used for teachers (Maslach Burnout Inventory-MBI) of Maslach and Jackson (1981). This is a questionnaire made up of 22 items which were divided into three subscales: Emotional Exhaustion-EE, 8 items, low Personal 
Accomplishment-PA, 9 items and Depersonalisation-DE, 5 items. Items were measured with a 4-point Likert-type scale whose answers ranged between "I quite disagree" (1), "I disagree more than I agree" (2), "I agree more than I disagree" (3), "I quite agree" (4). A general measure was obtained for all three scales by calculating the average of the scores obtained with the items belonging to each scale in such a way that the higher the score, the more burnout (more EE, less PA and more DE); and the lower the score, the less burnout (less EE, more PA and less DE). For further details, see Table 2.

\section{Data analysis}

To accomplish the objectives set out, descriptive and internal consistency analyses were done of the scales, as well as bivariate correlations among the variables were considered.

Subsequently, a hierarchical multiple regression analysis was carried out for each one of the dimensions of burnout (Emotional Exhaustion, low Personal Accomplishment and Depersonalisation) taken as dependent variables. The independent variables were introduced in the regression equation in four successive steps, but before they were standardized to minimize multicolineality, following the recommendations of Aiken and West (1991). In the first step demographic variables were introduced (gender, professional experience and educational level) to control their possible influence. Previous studies verified differences on burnout level in function of gender (Maslach, Schaufeli, \& Leiter, 2001; Salanova, Grau, \& Martínez, 2005), in function of professional experience (Anderson \&
Iwanicki, 1984; Borg \& Falzon, 1989) and in function of educational level (Byrne, 1999; Doménech-Betoret, 2009). In the second step the pedagogical barriers were introduced as independent variables to determine their impact on burnout. In the third step coping strategies were introduced to determine their impact on the burnout. In the fourth step interactions between pedagogical barriers and coping strategies were introduced (pedagogical barriers $\times$ active coping and pedagogical barriers $\times$ passive coping).

Finally, a second hierarchical multiple regression analysis was carried out for each type of coping strategies (active and passive) taken as dependent variables. The independent variables were introduced in the regression equation in two successive steps. In the first one the demographic variables were introduced (gender, professional experience and educational level) to control their possible influence. In the second, and last step, self-efficacy variables were introduced (instructional self-efficacy and management self-efficacy) to determine their predictive capacity on each type of coping strategy use.

\section{Results}

\section{Descriptive analyses}

Table 2 shows the number of items, factors, means, standard deviations and alpha coefficients for the scales used. In general, the scales present good internal consistency indices which range between .70 and .91 , except the passive coping scale, which has a slightly lower value (.67) and may be considered satisfactory, although not ideal/optimal, partly owing to the low number of items.

Table 2

Summary of the descriptive statistics and internal consistency of the scales $(n=724)$

\begin{tabular}{|c|c|c|c|c|}
\hline Factors & No. items & Variance $(\%)$ & Mean $(S D)$ & Cronbach's $\alpha$ \\
\hline \multicolumn{5}{|l|}{ Stressors $/$ barriers $($ minimum $=0$. maximum $=3$ ) } \\
\hline Classroom level: Students misbehaviour-demotivation (F1) & 7 & 32.70 & $2.16(.77)$ & .91 \\
\hline School level: Lack of shared decision making (F2) & 5 & 12.04 & $.51(.70)$ & .89 \\
\hline Administration level: Ambiguity demands (F3) & 6 & 8.72 & $1.50(1.03)$ & .93 \\
\hline Classroom level: Student diversity (F4) & 5 & 6.93 & $1.26(.70)$ & .85 \\
\hline School level: Workload (F5) & 4 & 5.46 & $.98(.81)$ & .81 \\
\hline Parents level: Insufficient involvement (F6) & 4 & 4.97 & $1.38(.94)$ & .88 \\
\hline \multicolumn{5}{|l|}{ Coping Strategies $($ minimum $=0$. maximum $=3$ ) } \\
\hline Passive coping & 4 & 33.3 & $.54(.49)$ & .67 \\
\hline Active coping & 3 & 24.7 & $2.52(.48)$ & .70 \\
\hline \multicolumn{5}{|l|}{ Personal variables: Self-efficacy $($ minimum $=1$. maximum $=4)$} \\
\hline Instructional Self-efficacy & 10 & 48.62 & $3.02(.46)$ & .84 \\
\hline Management Self-efficacy & 4 & 72.57 & $2.93(.61)$ & .87 \\
\hline \multicolumn{5}{|l|}{ Burnout Factors $($ minimum $=1$. maximum $=4$ ) } \\
\hline Emotional Exhaustion (EE) & 8 & 33.29 & $1.97(.62)$ & .86 \\
\hline Personal Accomplishment (PA) & 9 & 10.79 & $1.96(.45)$ & .83 \\
\hline Depersonalisation (DE) & 5 & 9.58 & $1.27(.42)$ & .76 \\
\hline
\end{tabular}




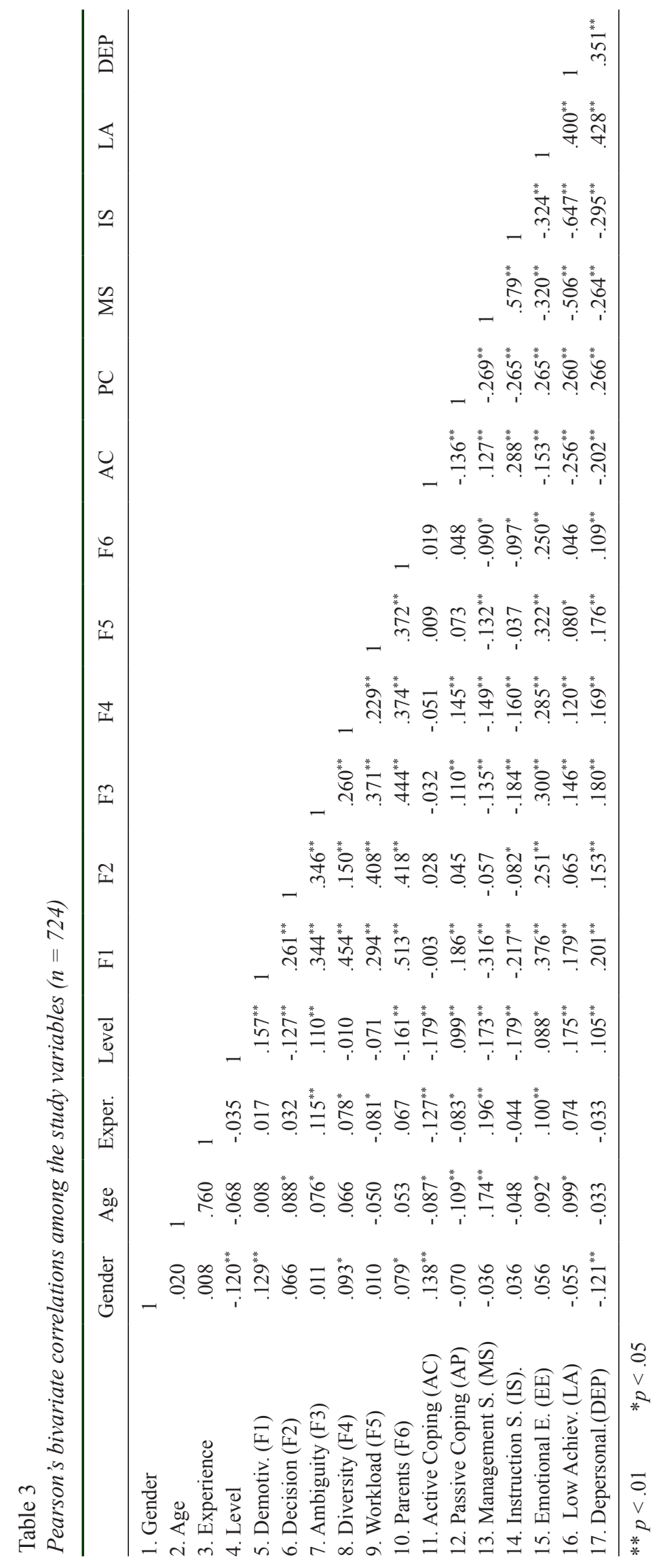


Table 3 shows Pearson's bivariate correlations among the variables which are in the expected direction. The pedagogical barriers correlate positively and significantly with the three dimensions of burnout. Management and teaching self-efficacy and the active coping strategies correlate negatively and significantly, while the passive coping strategies correlate positively and significantly. Finally, we see how self-efficacy correlates positively and significantly with the active coping strategies, but negatively and significantly with the passive coping strategies.

\section{Regression Analysis}

First of all, several hierarchical multiple regression analyses were performed to determine the main effects of the pedagogical barriers and the effects of the interaction between the pedagogical barriers and coping strategies on burnout.
Table 4 displays the results of the regression analysis in which emotional exhaustion is considered a dependent variable. These results reveal that female teachers suffer more emotional exhaustion than their male counterparts. They also show that emotional exhaustion increases with experience and that secondary school teachers suffer more emotional exhaustion than primary school teachers $(\beta=.87$, $p<.05 ; \beta=.98, p<.05$ and $\beta=.115, p<.01$ respectively). Finally, the data also reveal the main effects of the pedagogical barriers and coping strategies, and these results follow the expected directions. Most of the pedagogical barriers significantly predict emotional exhaustion (F1: Student misbehaviour and demotivation, $\beta=.229, p<.001$; F2: Lack of shared decision making, $\beta=.112 ; p<.01 ; \mathrm{F} 4$ : Student diversity, $\beta=.082, p<.05$ and F5: Workload, $\beta=$ $.194, p<.001$ ), accounting for around $20 \%$ of the explained variance. Both the passive and active coping strategies also predict emotional exhaustion significantly, and account for

Table 4

Hierarchical multiple regression analysis $(n=724)$. Dependent variable: Emotional exhaustion

\begin{tabular}{|c|c|c|c|c|}
\hline Independent variables & Beta & $t$ & $R^{2}$ & Change $R^{2}$ \\
\hline Step 1 (biographical variables) & & & .029 & $.029 * * *$ \\
\hline Gender $(1=$ male. 2 = female $)$ & .087 & $2.169^{*}$ & & \\
\hline Experience $(1=0-3$ years. $2=4-10$ years. $3=>10$ years $)$ & .098 & $2.466^{*}$ & & \\
\hline Level $(1=$ Primary. $2=$ Secondary $)$ & .115 & $2.870 * *$ & & \\
\hline Step 2 (pedagogical barriers) & & & .228 & $.199 * * *$ \\
\hline F1. Student misbehaviour-demotivation & .229 & $4.859 * * *$ & & \\
\hline F2. Lack of shared decision making & .112 & $2.682 * *$ & & \\
\hline F3. Ambiguity demands & .061 & 1.414 & & \\
\hline F4. Student diversity & .082 & $1.980^{*}$ & & \\
\hline F5. Workload & .194 & $4.686^{* * *}$ & & \\
\hline F6. Parents insufficient involvement & -.034 & -.704 & & \\
\hline Step 3 (coping strategies) & & & .281 & $.053 * * *$ \\
\hline Passive coping & .198 & $5.497 * * *$ & & \\
\hline Active coping & -.112 & $-3.101 * *$ & & \\
\hline Step 4 (barriers $\times$ coping strategies $)$ & & & .304 & .023 \\
\hline F1. Student misbehaviour-demotivation $\times$ active coping & .000 & -.001 & & \\
\hline F2. Lack of shared decision making $\times$ active coping & -.110 & -.508 & & \\
\hline F3. Ambiguity demands $\times$ active coping & .371 & 1.714 & & \\
\hline F4. Student diversity $\times$ active coping & -.014 & -.059 & & \\
\hline F5. Workload $\times$ active coping & -.100 & -.432 & & \\
\hline F6. Parents' insufficient involvement $\times$ active coping & -.046 & -.186 & & \\
\hline F1. Student misbehaviour-demotivation $\times$ passive coping & -.059 & -.389 & & \\
\hline F2. Lack of shared decision making $\times$ passive coping & .060 & .804 & & \\
\hline F3. Ambiguity demands $\times$ passive coping & .270 & $2.744 * *$ & & \\
\hline F4. Student diversity $\times$ passive coping & .117 & 1.134 & & \\
\hline F5. Workload $\times$ passive coping & .097 & 1.257 & & \\
\hline F6. Parents' insufficient involvement $\times$ passive coping & -.148 & -1.405 & & \\
\hline
\end{tabular}

${ }^{*} p<.05 \quad * * p<.01 \quad * * * p<.001$ 
around $5 \%$ of the explained variance $(\beta=.198, p<.001$ and $\beta=-.112, p<.01$, respectively).

Regarding the interaction effects, the results show that coping strategies (active and passive) do not modulate the relationship between pedagogical barriers and emotional exhaustion, which is contrary to that hypothesised.

Table 5 displays the results of the regression analysis in which low personal accomplishment is considered a dependent variable. These results indicate that as teachers gain more experience, they perceive themselves as having less efficacy at work. Furthermore, the results also show that primary school teachers perceive themselves as having more efficacy than secondary school teachers $(\beta=.104$, $p<.05 ; \beta=.178, p<.001$, respectively). Finally, the results also show the main effects of pedagogical barriers and coping strategies. The primary pedagogical barriers that predict low personal accomplishment are F1: Student misbehaviour and demotivation $(\beta=.155, p<.001)$ and F6: Parents' insufficient involvement $(\beta=-0.111$; $p<.05)$ which accounts for around $5 \%$ of the variance. Coping strategies have a significant effect on low personal accomplishment, are positive for the passive strategies $(\beta=.193, p<.001)$, but negative for the active strategies $(\beta=-.204, p<.001)$, and explain around $8 \%$ of the variance.

Regarding the interaction effects, the results show that other than having a significant main effect, coping strategies also modulate some of the relationships between pedagogical barriers and low personal accomplishment; for example, Lack of shared decision-making $\times$ active coping $(\beta=-.502, p<.05)$ and Student misbehaviour-demotivation $\times$ passive coping $(\beta=.311 ; p<.05)$. In order to present a more in-depth interpretation of these results, the interactions have been graphically represented (see Figures 1 and 2). Figure 1 depicts that those teachers who use the active coping strategies more often to cope with the pedagogical

Table 5

Hierarchical multiple regression analysis $(n=724)$. Dependent variable: Low personal accomplishment

\begin{tabular}{|c|c|c|c|c|}
\hline Independent variables & Beta & $t$ & $R^{2}$ & Change $R^{2}$ \\
\hline Step 1 (biographic variables) & & & .044 & $.044 * * *$ \\
\hline Gender $(1=$ male. $2=$ female $)$ & -.031 & -.780 & & \\
\hline Experience $(1=0-3$ years. $2=4-10$ years. $3=>10$ years $)$ & .104 & $2.601 *$ & & \\
\hline Level $(1=$ Primary. $2=$ Secondary $)$ & .178 & $4.439 * * *$ & & \\
\hline Step 2 (pedagogical barriers) & & & .089 & $.045 * * *$ \\
\hline F1. Student misbehaviour-demotivation & .155 & $3.022 * *$ & & \\
\hline F2. Lack of shared decision making & .060 & 1.333 & & \\
\hline F3. Ambiguity demands & .087 & 1.834 & & \\
\hline F4. Student diversity & .065 & 1.428 & & \\
\hline F5. Workload & .015 & .327 & & \\
\hline F6. Parents' insufficient involvement & -.111 & $-2.113 *$ & & \\
\hline Step 3 (active and passive coping Strategies) & & & .173 & $.084 * * *$ \\
\hline Passive coping & .193 & $4.943 * * *$ & & \\
\hline Active coping & -.204 & $-5.248 * * *$ & & \\
\hline Step 4 (barriers $\times$ coping strategies) & & & .207 & $.034 *$ \\
\hline F1. Student misbehaviour-demotivation $\mathrm{s} \times$ active coping & -.428 & -1.439 & & \\
\hline F2. Lack of shared decision making $\times$ active coping & -.502 & $-2.159 *$ & & \\
\hline F3. Ambiguity demands $\times$ active coping & .282 & 1.206 & & \\
\hline F4. Student diversity $\times$ active coping & -.143 & -.544 & & \\
\hline F5. Workload $\times$ active coping & -.184 & -.734 & & \\
\hline F6. Parents' insufficient involvement $\times$ active coping & .477 & 1.795 & & \\
\hline F1. Student misbehaviour-demotivation $\times$ passive coping & .311 & $1.998^{*}$ & & \\
\hline F2. Lack of shared decision making $\times$ passive coping & .133 & 1.660 & & \\
\hline F3. Ambiguity demands $\times$ passive coping & .027 & .250 & & \\
\hline F4. Student diversity $\times$ passive coping & -.019 & -.168 & & \\
\hline F5. Workload $\times$ passive coping & -.013 & -.155 & & \\
\hline F6. Parents' insufficient involvement $\times$ passive coping & -.016 & -.138 & & \\
\hline
\end{tabular}

$* p<.05 \quad * * p<.01 \quad * * * p<.001$ 


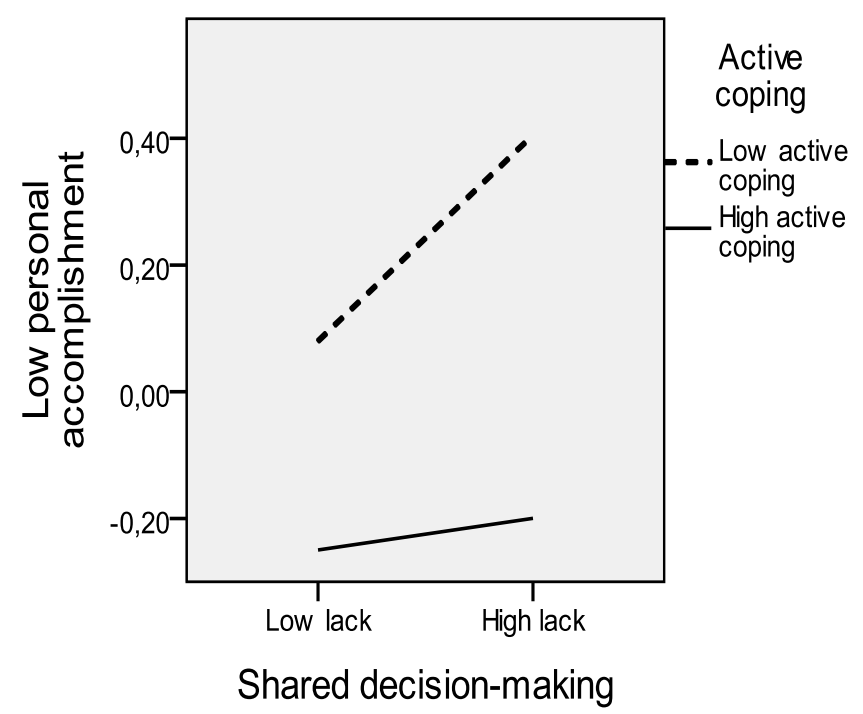

Figure 1. Interaction between shared decision making $\times$ active coping.

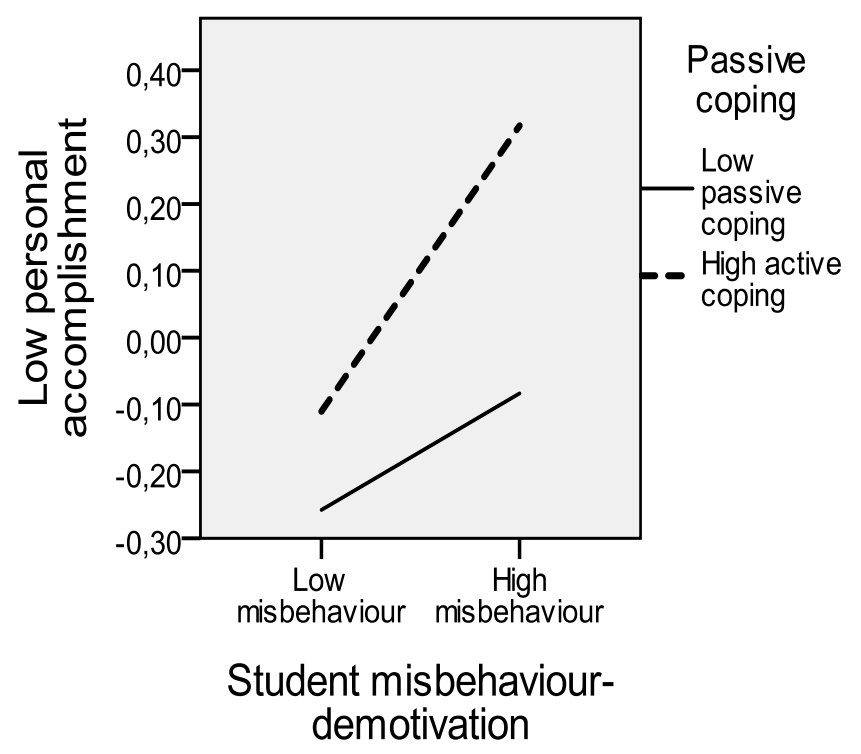

Figure 2. Interaction between student misbehaviour-demotivation $\times$ passive coping.

barrier named "Lack of shared decision making" have less feelings of low personal accomplishment, whereas those who use the active coping strategies less often report having more feelings of low personal accomplishment. Figure 2 shows how the teachers who use the passive coping strategies more often to cope with the pedagogical barrier named "Student misbehaviour-demotivation" have more feelings of low personal accomplishment, and vice versa.

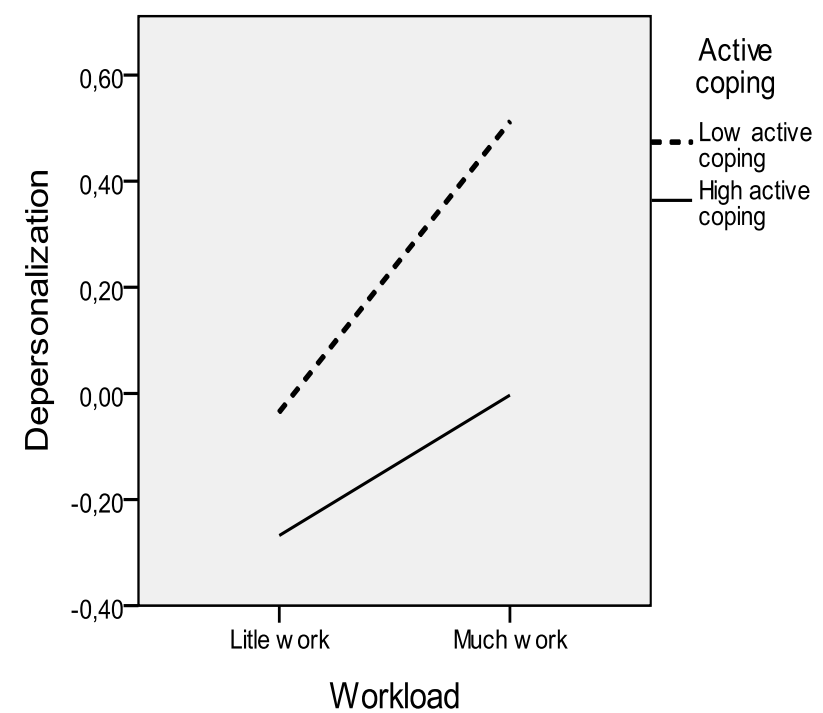

Figure 3. Interaction between workload $\times$ active coping.

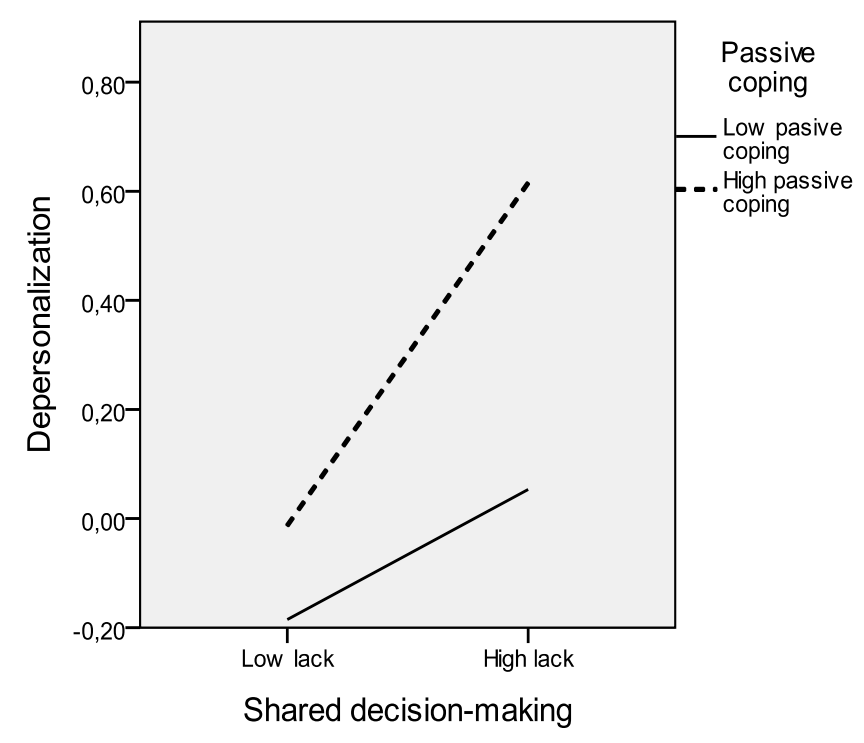

Figure 4. Interaction between shared decision making $\times$ passive coping.

Table 6 displays the results of the regression analysis in which depersonalisation is considered a dependent variable. These results indicate that male teachers suffer more depersonalisation than female teachers. Moreover, the data reveal that secondary school teachers suffer more depersonalisation than primary school teachers $(\beta=-0.87$, $p<.05$ and $\beta=.104, p<.05$, respectively). Finally, the results also show the main effects of both the pedagogical 
Table 6

Hierarchical multiple regression analysis $(n=724)$. Dependent variable: Depersonalisation

\begin{tabular}{|c|c|c|c|c|}
\hline Independent variables & Beta & $t$ & $R^{2}$ & $\begin{array}{l}\text { Change } \\
R^{2}\end{array}$ \\
\hline Step 1 (biographical variables) & & & .022 & $.022 * *$ \\
\hline Gender $(1=$ male. $2=$ female $)$ & -.087 & $-2.164^{*}$ & & \\
\hline Experience $(1=0-3$ years. $2=4-10$ years. $3=>10$ years $)$ & -.035 & -.885 & & \\
\hline Level $(1=$ Primary. 2 = Secondary $)$ & .104 & $2.588^{*}$ & & \\
\hline Step 2 (pedagogical barriers) & & & .108 & $.087 * * *$ \\
\hline F1. Student misbehaviour-demotivation & .115 & $2.289 *$ & & \\
\hline F2. Lack of shared decision-making & .128 & $2.876^{* *}$ & & \\
\hline F3. Ambiguity demands & .079 & 1.711 & & \\
\hline F4. Student diversity & .088 & $1.980 *$ & & \\
\hline F5. Workload & .104 & $2.336^{*}$ & & \\
\hline F6. Parents' insufficient involvement & -.089 & -1.737 & & \\
\hline Step 3 (coping strategies) & & & .176 & $.068 * * *$ \\
\hline Passive coping & .181 & $4.681 * * *$ & & \\
\hline Active coping & -.179 & $-4.630 * * *$ & & \\
\hline Step 4 (barriers $\times$ coping strategies) & & & .246 & $.070 * * *$ \\
\hline F1. Student misbehaviour-demotivation $\times$ active coping & -.071 & -.249 & & \\
\hline F2. Lack of shared decision making $\times$ active coping & -.035 & -.158 & & \\
\hline F3. Ambiguity demands $\times$ active coping & .141 & .631 & & \\
\hline F4. Student diversity $\times$ active coping & .331 & 1.315 & & \\
\hline F5. Workload $\times$ active coping & -.687 & $-2.900 * *$ & & \\
\hline F6. Parents' insufficient involvement $\times$ active coping & .048 & .189 & & \\
\hline F1. Student misbehaviour-demotivation $\times$ passive coping & -.071 & -.448 & & \\
\hline F2. Lack of shared decision making $\times$ passive coping & .302 & $3.881 * * *$ & & \\
\hline F3. Ambiguity demands $\times$ passive coping & .227 & $2.214^{*}$ & & \\
\hline F4. Student diversity $\times$ passive coping & .067 & 623 & & \\
\hline F5. Workload $\times$ passive coping & .054 & 678 & & \\
\hline F6. Parents' insufficient involvement $\times$ passive coping & -.105 & -.966 & & \\
\hline
\end{tabular}

$* p<.05 \quad * * p<.01 \quad * * * p<.001$

barriers and coping strategies. As expected, these variables followed the expected pattern. Most of the pedagogical barriers (F1: Student misbehaviour-demotivation, $\beta=.115$, $p<.05$; F2: Lack of shared decision making, $\beta=.128, p<$ .01 ; F4: Student diversity, $\beta=.088, p<.05$ and F5: Workload, $\beta=.104, p<.05)$ significantly, yet moderately, predicted depersonalisation which accounted for around $9 \%$ of the variance explained. Coping strategies also had a significant effect (accounting for around 7\% of the total variance) on depersonalisation, were positive for the passive strategies $(\beta=.181 ; p<.001)$, but negative for the active strategies $(\beta=-0.179 ; p<.001)$.

Regarding the interaction effects, the results reveal that other than having a significant main effect, coping strategies also modulate some of the relationships between pedagogical barriers and Low personal accomplishment. For example, Workload $\times$ active coping $(\beta=-0.687, p$
$<.01)$, Lack of shared decision making $\times$ passive coping $(\beta=.302, p<.001)$ and Student ambiguity demands $\times$ passive coping $(\beta=.227, p<.05)$. In order to present an in-depth interpretation of these results, the interactions have been graphically represented (see Figures 3, 4 and 5). Figure 3 illustrates how teachers use the active coping strategies more often to cope with the barrier named "Workload" have less feelings of depersonalisation, and vice versa. Figure 4 shows that the teachers who use the passive coping strategies more often to cope with the barrier named "Lack of shared decision making" have more feelings of depersonalisation, and vice versa. Finally, Figure 5 reveals that the teachers who use the passive coping strategies more often to cope with the barrier named "Ambiguity demands" report more depersonalisation, and vice versa. 


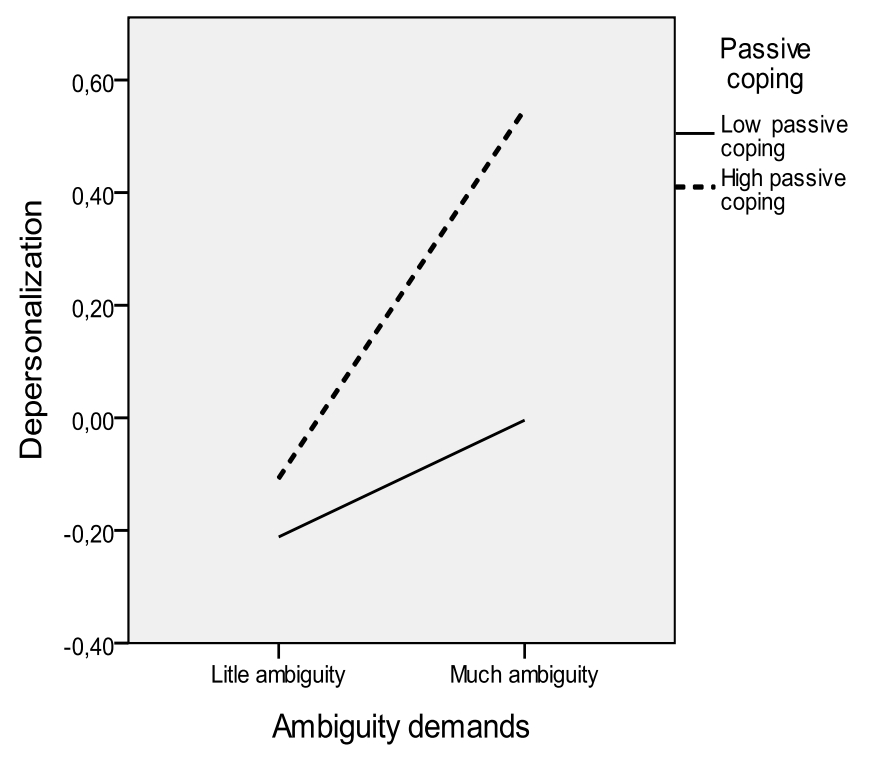

Figure 5. Interaction between ambiguity demands $\times$ passive coping.
Finally, two additional hierarchical multiple regression analyses were conducted to determine the effects of self-efficacy (instructional and management) on coping strategies (active and passive) after having controlled the effects of the biographical variables. Table 7 presents the results of the regression analysis by considering the passive coping strategies as a dependent variable. These results reveal that secondary school teachers use passive coping more often than primary school teachers $(\beta=.104$; $p<.05)$. Moreover, the data indicate that instructional and management self-efficacy have a significant and negative effect on the passive coping strategies $(\beta=-0.193 ; \mathrm{p}<.001$ and. $=-0.136 ; p<.01$ respectively)

Table 8 displays the results of the regression analysis by considering active coping as a dependent variable. These results indicate that female secondary school teachers use active coping more often than male teachers and that active coping strategies decrease with professional experience. Furthermore, the data reveal that primary school teachers use active coping more than secondary school teachers $(\beta=.112, p<.01 ; \beta=-0.127, p<.01$ and $\beta=-0.171 ; p$ $<.001$, respectively). Finally, the results also show that instructional self-efficacy has a significant and positive effect on the active coping strategies $(\beta=.249, p<.001)$.

Table 7

Hierarchical multiple regression analysis $(n=724)$. Dependent variable: Passive coping

\begin{tabular}{|c|c|c|c|c|}
\hline Independent variables & Beta & $t$ & $R^{2}$ & Change $R^{2}$ \\
\hline Step1 (biographical variables) & & & .019 & $.019 * *$ \\
\hline Gender $(1=$ male $2=$ female $)$ & -.049 & -1.220 & & \\
\hline Experience $(1=0-3$ years, $2=4-10$ years, $3=>10$ years $)$ & -.063 & -1.581 & & \\
\hline Level $(1=$ Primary. $2=$ Secondary $)$ & .104 & $2.591 *$ & & \\
\hline Step 2 (Self-efficacy variables) & & & .101 & $.082 * * *$ \\
\hline Management Self-efficacy & -.193 & $-3.916^{* * *}$ & & \\
\hline Instructional Self-efficacy & -.136 & $-2.821 * *$ & & \\
\hline
\end{tabular}

$* p<.05 \quad * * p<.01 \quad * * * p<.001$

Table 8

Hierarchical multiple regression analysis $(n=724)$. Dependent variable: Active coping

\begin{tabular}{|c|c|c|c|c|}
\hline Independent variables & Beta & $t$ & $R^{2}$ & Change $R^{2}$ \\
\hline Step 1 (biographical variables) & & & .062 & $.062 * * *$ \\
\hline Gender $(1=$ male. $2=$ female $)$ & .112 & $2.880^{* *}$ & & \\
\hline Experience $(1=0-3$ years, $2=4-10$ years. $3=>10$ years $)$ & -.127 & $-3.262 * *$ & & \\
\hline Level (1= Primary. $2=$ Secondary $)$ & -.171 & $-4.373 * * *$ & & \\
\hline Paso 2 (Self-efficacy variables) & & & .129 & $.067 * * *$ \\
\hline Management Self-efficacy & .025 & .511 & & \\
\hline Instructional Self-efficacy & .249 & $5.284 * * *$ & & \\
\hline
\end{tabular}

${ }^{*} p<.05 \quad * * p<.01 \quad * * * p<.001$ 


\section{Discussion}

This research work studies teacher burnout from a view point which is instructional as it is based on the idea that the obstacles hindering the teaching process conducted by teachers, and which also hinder learning objectives from being fulfilled, may predict teacher burnout.

The pedagogical barriers scale used, the main instrument employed in this study, shows good, valid and reliable psychometric properties.

The first objective consisted in examining the predictive capacity of the pedagogical barriers on teacher burnout. The results obtained from the hierarchical multiple regression analyses performed show positive and significant main effects of most of the pedagogical barriers on some burnout dimensions, indicating that when these barriers increase, teacher burnout also increases. Student misbehaviour and demotivation (F1) are seen as being the factor with better global predictive capacity on burnout, particularly on emotional exhaustion and low personal accomplishment. Lack of shared decision making (F2) and Workload (F5) are also seen to be good predictors of depersonalisation and emotional exhaustion. Finally, Student diversity emerges as a significant but less important predictor of depersonalisation. In general, these results follow the expected pattern and apparently confirm that the pedagogical barriers, which interfere with the teaching process undertaken in the classroom, are good predictors of teaching burnout, and explain up to $20 \%$ of the emotional exhaustion variance. However, their predictive capacity on the other burnout dimensions is more moderate. It is important to take into account the impact that the pedagogical barriers have on emotional exhaustion since this construct can indirectly affect the other two dimensions (low personal accomplishment and depersonalisation), as recent studies have verified (Doménech-Betoret, 2009). It is also important to underline that the explanatory capacity of the pedagogical barriers on burnout may increase if we consider teacher motivation (Pines, 1993). According to this author, the burnout syndrome develops in workers who are highly motivated by their work, are identified with their work and who attempt to accomplish major objectives. In short, we can affirm that the first hypothesis, that of pedagogical barriers being good predictors of burnout, has been supported.

The second objective consisted in analysing whether coping strategies modulate the relationship between pedagogical barriers and the burnout syndrome. The results obtained, described in the Results section, reveal that coping strategies (active and passive) modulate the relationship between several pedagogical barriers and low personal accomplishment (lack of shared decision making $\times$ active coping has a significant, negative effect, while student misbehaviour and demotivation $\times$ passive coping has a significant, positive effect).
Specifically, it appears that poor active coping in highly lacking situations generates more feelings of low personal accomplishment, whereas a greater use of passive coping increases low personal accomplishment in high misbehaviour situations. Basically, it seems that using active coping less often and passive coping more frequently increases depersonalisation.

Coping strategies also modulate the relationship between several pedagogical barriers and depersonalisation (Workload $\times$ active coping have a significant, negative effect; while both Lack of shared decision making $\times$ passive coping and Ambiguity demands $\times$ passive coping have a significant, positive effect). Specifically, the results seem to reveal that the teachers who use active coping less often in hard workload situations suffer more depersonalisation. Furthermore, these results indicate that the teachers who use passive coping more often in highly lacking situations suffer more depersonalisation. Finally, the data also show that the teachers who use passive coping more often in high ambiguity situations suffer increased depersonalisation. In short, it seems that using active coping less often and passive coping more often enhances depersonalisation.

However, this study has not verified whether coping strategies (active and passive) modulate the relationship between pedagogical barriers and emotional exhaustion dimension since the coefficient of determination (R2) was not significant for this dimension. Therefore, these results suggest that those teachers who use the active coping strategies more often to overcome pedagogical barriers feel more efficacy in their work and report less depersonalisation, despite the moderator role of coping strategies on emotional exhaustion not being proved. These results are similar to those obtained by other authors in previous studies whose data have shown that many authors claim that the use of either active or passive strategies does not prevent emotional exhaustion (Anderson, 2000; Stevens, \& Higgins, 2002), or that their relationship with emotional exhaustion is scarce (Jenaro-Riol, Flores-Robaina, \& González-Gil, 2007). Besides, this dimension has been considered the central characteristic of the syndrome (Maslach, Schaufeli, \& Leiter, 2001). This fact could be explained in the light of the genesis of burnout proposed by Leiter and Maslach (1988). According to these authors, the three dimensions of burnout appear sequentially in time. Thus the first dimension to arise is emotional exhaustion and, consequently, depersonalisation appears. Finally due to the negative and cynic behaviours adopted, feelings of low personal accomplishment also appear. In this context, coping strategies apparently act when burnout has been triggered, perhaps because the last two stages (depersonalisation and low personal accomplishment) are more closely related with feelings of professional efficacy. More research is required to do an in-depth analysis of the relationship between burnout and coping strategies. 
Based on these arguments, we confirm that the second hypothesis, that coping strategies modulate the relationship between pedagogical barriers and burnout, has been partially proved. Nonetheless, the obtained results reinforce the idea defended by many authors (Anderson, 2000; Blanch, Aluja, \& Biscarri, 2002; Hernández, Olmedo, \& Ibáñez, 2004) when they assert the modulator role played by coping strategies in the aetiology of burnout.

Finally, we should point out that the modulator role played by coping strategies may be influenced by the support perceived by the subjects to use the active coping strategies since developing this type of strategies implies greater effort and dedication when compared with using the passive or avoidance strategies. Therefore, the modulator effect of coping strategies between the pedagogical barriers and the burnout relationship could increase if we consider the other variables relating with perceived supports, which is in line with the Job Demands-Resources (JD-R) Model proposed by Demerouti, Bakker, Nachreiner, and Schaufeli (2001). Although the results are not conclusive, we believe that the coping strategy variable should be considered in burnout models in which barrier factors are involved, which may be general (for example, Harrison, 1983 and Pines, 1993) and specific (for example Blase, 1982; DoménechBetoret, 2009).

The third objective consisted in analysing the relationship between self-efficacy and coping strategies. A significant, positive relationship between self-efficacy (instruction and management) and the active coping strategies, and a negative, significant relationship between self-efficacy (instructional and management) and the passive coping strategies, is hypothesised. In general, the data obtained in the two hierarchical regression analyses conducted (one for each type of coping) are in the expected direction and show that self-efficacy (instructional and management) increases the frequency of using the active coping strategies in order to overcome the pedagogical barriers, whereas the use of the passive coping strategies decreases. Therefore, we can assert that the third hypothesis has been proved to a great extent. These results coincide with those obtained in previous research works (Jex, Bliese, Buzzel, \& Primeau, 2001; Salanova, Grau, \& Martínez, 2005), and they support Bandura's Social Cognitive Theory $(1999,2001)$ which argues that people with high self-efficacy trust their abilities more to effectively respond to the environment stimulus and to maintain self-control. Self-efficacy has been associated with high levels of motivation, effort and perseverance with the task (Compeau \& Higgins, 1995; Hill, Smith, \& Mann, 1987).

\section{Limitations}

Among the main limitations of this work we find the exclusive use of self-reporting techniques to collect information. Experts recommend combining this type of measuring instruments with other more qualitative ones as they argue that the responses to the questionnaire may be influenced by personal or social values. The second main limitation is the representativeness of the study sample. The teachers who participated in this study did so voluntarily, so there was no random selection involved to ensure that the sample was representative of the study population. Therefore, caution is needed when generalising these results. The third major limitation is the moderate reliability obtained in some of the instruments used; for example, the coping strategies scale. Finally, the forth major limitation refers to a cross sectional design of the study, not longitudinal, which prevent from getting information over the time as well as interpret the relationship obtained in terms of causality.

\section{Practical implications}

Despite these limitations, this study provides new data to previous research work done on the issue of teacher burnout from a more operative and teaching viewpoint. Apart from contributing to the understanding of this phenomenon, this work also presents practical implications to reduce teacher burnout. On the one hand and regarding the initial teacher training of primary and secondary teachers, it would firstly be recommendable to develop attitudes that generate active coping strategies so teachers can respond when faced with the difficulties they encounter in their profession rather than being overcome by them. Secondly, it would be necessary to develop and enhance skills and capacities related with teaching efficacy (the teaching role) and group-class management (management role). One way to accomplish this would be to increase practical periods in schools. It seems that the new study programmes currently being managed in universities in the common European area are moving in this direction. On the other hand, and concerning continuing teacher training, it would also be recommendable to develop training actions that move in the same direction, but not only at the personal level, as these actions have not proved very successful when they were not programmed at the school level. Therefore, training actions should be implemented simultaneously at both the personal and organisational levels (Friedman, 1999; Nytro, Mikkelsen, Bohle, \& Quinlan, 2000).

\section{Future research}

Now we propose several suggestions to continue studying in depth this line of research in the future. Firstly, and based on the demands-resources theory (Job DemandsResources Model) proposed by Demerouti, Bakker, Nachreiner and Schaufeli (2001), it would be interesting to have other demands available that are expected of teachers apart from those that fulfil the learning objectives, and which could explain an additional increase of the variance of burnout. In this sense, it would be interesting to have demands related with several types of tasks: bureaucratic, 
orientating, tutorial, conflict-solving, training, team work tasks with colleagues, etc. These tasks and some other types are demands expected of teachers who, in most cases, are not trained for them. So they may generate high levels of burnout. Secondly, and also based on the demands-resources theory, it would also be interesting to have new personal resources and to consider other self-efficacy modalities such as self-efficacy in achieving support for colleagues and managerial posts (Brouwers, Evers, \& Tomic, 2001), or self-efficacy in personal relationships (Friedman, 2003), because relationships among colleagues are very important in the school context as teachers do not work alone but interact with other professionals (which, as we mentioned before, is one of the current demands for teachers). Thirdly, reviewing the measuring instrument used for the coping strategies and its extension by introducing new items and new subscales (search for specialised support, requesting training, etc.) is recommended. The final recommendation would be to conduct this study using other more qualitative information collection techniques simultaneously with selfreport instruments.

\section{References}

Aiken, L. S., \& West, S. G. (1991). Multiple regression: Testing and interpretation interactions. Newbury Park, CA: Sage.

Anderson, D. G. (2000). Coping strategies and burnout among veteran child protection workers. Child Abuse \& Neglect, 24, 839-848.

Anderson, M. B., \& Iwanicki, E. F. (1984). Teacher motivation and its relationship to burnout. Educational Administration Quarterly, 20, 109-132.

Bandura, A. (1986): Social foundations of thought and action: A social cognitive theory. Englewood Cliffs, NJ: Prentice Hall.

Bandura, A. (1997). Self-efficacy: The exercise of control. New York, NY: Freeman.

Bentler, P. M. (2006). EQS Structural Equations Program Manual. Encino, CA: Multivariate Software.

Blanch, A., Aluja, A., \& Biscarri, J. (2002). Síndrome de quemarse en el trabajo (burnout) y estrategias de afrontamiento: un modelo de relaciones estructurales [Burnout and coping strategies: a structural relationship model]. Revista de Psicología del Trabajo y de las Organizaciones, 18, 57-74.

Blase, J. J. (1982). A Social-Psychological Grounded Theory of Teacher Stress and Burnout. Educational Administration Quarterly, 18, 93-113.

Borg, M. G., \& Falzon, J. M. (1989). Stress and job satisfaction among primary school teachers in Malta. Educational Review, 41, 271-279.

Brouwers, A. (2000). A longitudinal study of teacher burnout and perceived self-efficacy in classroom management. Teaching and Teacher education, 16(2), 239-253

Brouwers, A., Evers, W. J. G., \& Tomic, W. (2001). Self-efficacy in eliciting social support and burnout among secondaryschool teachers. Journal of Applied Social Psychology, 31(7), 1474-1491.
Byrne, B. M. (1999): The nomological network of teacher burnout: A literature review and empirically validated model. In R. Vandenberghe, \& A. M. Huberman (Eds.) Understanding and preventing teacher burnout (pp. 15-37). Cambridge, MA: Cambridge University Press.

Calvete, E., \& Villa, A. (1999). Estrés y burnout docente: influencia de variables cognitivas [Stress and teaching burnout: influence of cognitive variables]. Revista de Educación, 319, 291-303.

Compeau, D. R., \& Higgins, C. A. (1995). Computer self-efficacy: development of a measure and initial test, MIS Quarterly, 19, 189-211.

Chan, D. W. (1998). Stress, Coping Strategies and Psychological Distress Among Secondary School Teachers in Hong Kong. American Educational Research Journal, 35, 145-163.

Chan, D. W. (2002). Stress, Self-Efficacy, Social Support, and Psychological Distress Among Prospective Chinese Teachers in Hong Kong. Educational Psychology, 22, 557-569

Chernis, C. (2003). Role of professional self-efficacy in the etiology and amelioration of burnout. In W. Schaufeli, \& C. Maslach (eds.). Professional burnout: recent developments in theory and research. Series in applied psychology: Social issues and questions (pp. 135-149). Philadelphia: Taylor \& Francis.

Demerouti, E., Bakker, A. B., Nachreiner, F., \& Schaufeli, W. B. (2001). The job demands-resources model of burnout. Journal of Applied Psychology, 86, 499-512.

Dick, R. van, \& Wagner, U. (2001). Stress and strain in teaching: A structural equation approach. British Journal of Educational Psychology, 71, 243-259.

Doménech, F. (2005): Autoeficacia, recursos escolares de afrontamiento y agotamiento docente en profesores de secundaria [Self-Efficacy, school resources and burnout among secondary school teachers]. Infancia y Aprendizaje, 28, 471-483.

Doménech-Betoret, F. (2006). Stressors, Self-Efficacy, Coping resources and Burnout among Secondary School Teachers in Spain. Educational Psychology, 26, 519-539

Doménech-Betoret, F. (2009). Self-efficacy, school resources, job stressors and burnout among Spanish primary and secondary school teachers: A structural equation approach. Educational Psychology, 29, 45-68.

Durán, M. A., Extremera, N., Montalbán, M. \& Rey, L. (2005). Engagement y Burnout en el ámbito docente: Análisis de sus relaciones con la satisfacción laboral y vital en una muestra de profesores [Engagement and Burnout in teaching environment: Analysis of their relationships with job and life satisfaction in a sample of teachers]. Revista de Psicología del Trabajo y de las Organizaciones, 21, 145-158.

Endler, N. S., \& Parker, J. D. A. (1990). Multidimensional assessment of coping: a critical evaluation. Journal of personality and Social Psychology, 58, 844-854.

Flores, M. D., \& Fernández-Castro, J. (2004). Creencias de los profesores y estrés docente en función de la experiencia profesional [Beliefs of teachers and teaching stress based on professional experience]. Estudios de Psicología, 25(3), 343357. 
Folkman, S., \& Lazarus, R. S. (1980). An analysis of coping in a middle-aged community sample. Journal of Health and Social Behavior, 21, 219-239.

Folkman, S., \& Lazarus, R. S. (1985). If it changes it must be a process: A study of emotion and coping during three stages of a college examination. Journal of Personality and Social Psychology, 48, 150-170.

Friedman, I. A. (1999). Turning Our Schools into a Healthier Workplace: Bridging between Professional Self-Efficacy and Professional Demands. In Ronald Vandenberghe, \& A. Michael Huberman (Eds.), Understanding and Preventing Teacher Burnout (pp. 166-176). Cambridge University Press.

Friedman, I. A. (2003). Self-efficacy and burnout in Teaching: The importance of interpersonal-relations efficacy. Social Psychology of Education, 6(3), 191-215.

Gil-Monte, P. R., \& Peiró, J. M. (1999). Perspectivas teóricas y modelos interpretativos para el estudio del síndrome de quemarse por el trabajo [Theoretical perspectives and interpretative models for the study of Burnout at work]. Anales de Psicología, 15(2), 261-268.

Harrison, W. D. (1983). A social competence model of burnout. In B. A. Farber (ed). Stress and burnout in the human services professions (1985, 20 ed., pp. 29-39). New York: Pergamon Press.

Harvey, L., \& Green, D. (1993): «Defining Quality». Assessment \& Evaluation in Higher Education, 18(1), 9-34

Heinrich, R., Molenda, M., Russell, J. D., \& Smaldino, S. E. (1996). Instructional media and technologies for learning. Englewood Cliffs, NJ: Merrill.

Hernández, G. L., Olmedo, E., \& Ibáñez, I. (2004). Estar quemado (burnout) y su relación con el afrontamiento. International Journal of Clinical and Health Psychology, 4, 323-336.

Hill, T., Smith, N. D., \& Mann, M. F. (1987). Role of efficacy expectations in predicting the decision to use advanced technologies: the case of computers. Journal of Applied Psychology, 72, 307-313.

Jenaro-Riol, C., Flores-Robaina, N., \& González-Gil, F. (2007). International Journal of Clinical and Health Psychology, 7(1), 107-121

Jex, S. M., Bliese, P. D., Buzzel, S., \& Primeau, J. (2001). The impact of self-efficacy on stressor-strain relations: Coping style as an exploratory mechanism. Journal of Applied Psychology, 86(3), 401-409.

Kelchtermans, G. (1999). Teaching career: Between burnout and fading away? Reflexions from a narrative and biographical perspective. In Ronald Vandenberghe, \& A. Michael Huberman (Eds.), Understanding and preventing teacher burnout (pp. 176-191). Cambridge: Cambridge University Press

Lazarus, R. S. (1966). Psychological stress and the coping process. New York: McGraw-Hill.

Lazarus, R. S., \& Folkman, S. (1984). Stress, Appraisal and coping. New York: Springer.

Lens, W., \& Neves de Jesus, S. (1999). A Psychosocial interpretation of teacher stress and burnout. In Ronald Vandenberghe, \& A. Michael Huberman (Eds.), Understanding and preventing teacher burnout (pp. 192-201). Cambridge: Cambridge University Press
Leiter, M. P. (1991). Coping patterns as predictors of burnout: the function of control and escapist coping patterns. Journal of Organizational Behavior, 12, 123-144.

Leiter, M. P., \& Maslach, C. (1988). The impact of interpersonal environment on burnout and organizational commitment. Journal of Organizational Behavior, 9, 297-308.

LOCE (2002). Ley Orgánica de Calidad de la Educación [Organic law on educational quality]. Madrid: Boletín Oficial del Estado.

LODE (1985). Ley Orgánica del Derecho a la Educación [Organic law on educational right]. Madrid: Boletín Oficial del Estado.

LOE (2005). Ley Orgánica de Educación [Organic law on education]. Madrid: Boletín Oficial del Estado.

LOGSE (1990). Ley orgánica de Ordenación General del Sistema Educativo [Organic law on general educational system]. Madrid: Boletín Oficial del Estado.

Lorente, L., Salanova, M., Martinez, I., \& Schaufeli, W. (2008). Extension of the job Demands-Resources model in the prediction of burnout and engagement among teachers over time. Psicothema, 20(3), 354-360.

Llorens, S., García-Renedo, M., \& Salanova, M. (2005). Burnout como consecuencia de una crisis de eficacia: un estudio longitudinal en profesores de secundaria [Burnout as a result of efficacy crisis: A longitudinal study in secondary school teachers]. In I. Martínez y M. Salanova (Dirs.) Burnout en la enseñanza, Revista de Psicología del Trabajo y las Organizaciones, 21(1-2), 55-70.

Manthei, R., Gilmore, A., Tuck, B., \& Adair, V. (1996). Teacher stress in intermediate school. Educational Research, 38, 3-19.

Maslach, C., \& Jackson, S. E. (1981). The Maslach burnout inventory. Research Edition. Palo Alto, CA: Consulting Psychology Press.

Maslach, C., \& Jackson, S. E. (1986). The Maslach burnout inventory. Research Edition. Palo Alto, CA: Consulting Psychology Press.

Maslach, C., Jackson, S. E., \& Leiter, M. P. (1996). The Maslach burnout inventory. ( $3^{\text {rd }}$ Ed. ). Palo Alto, CA: Consulting Psychology Press.

Maslach, C., \& Schaufely, W. B., \& Leiter (2001). Job burnout. Annual Review of Psychology, 52, 397-422.

Moriana, J. A., \& Herruzo, J. (2004). Estrés y burnout en profesores. International Journal of Clinical and Health Psychology, 4(3), 597-621.

Nytro, K., Mikkelsen, A., Bohle, P., \& Quinlan, M. (2000). An appraisal of key factors in the implementation of occupational stress interventions. Work and Stress, 14, 213-225.

Pines, A. M. (1993). Burnout: "An existential perspective”. In W. B. Schaufeli, C. Maslach, \& T. Marek (Eds.), Professional burnout: Recent development in theory and research (pp. 3351). London: Taylor \& Francis.

Pithers , R. T., \& Fogarty. G. J. (1995). Occupational stress among vocational teachers. British Journal of Educational Psychology, 65, 3-14. 
Pithers , R. T., \& Soden, R. (1998). Scottish and Australian teacher stress and strain: a comparative study. British Journal of Educational Psychology, 68, 269-279.

Salanova, M., Grau, R., \& Martínez, I. (2005). Demandas laborales y conductas de afrontamiento: el rol modulador de la autoeficacia profesional [Labour demands and coping behavior: the modulator role of professional self-efficacy]. Psicothema, 17(3), 390-395.

Salanova, M., Martínez, I., \& Lorente, L. (2005). ¿Cómo se relacionan los obstáculos y facilitadores organizacionales con el burnout docente? Un estudio longitudinal [How relate the obstacles and organizational facilitators with teaching burnout?: a longitudinal study]. In I. Martínez \& M. Salanova (Dirs.) Burnout en la enseñanza, Revista de Psicología del Trabajo y las Organizaciones, 21(1-2), 37-54.

Salanova, M., Cifre, E., Grau, R. Ma., Llorens, S., \& Martínez, M. I. (2005). Antecedentes de la autoeficacia en profesores y estudiantes universitarios: un modelo causal [Antecedents of self-efficacy in college teachers and students: A causal model]. Revista de Psicología del trabajo y de las Organizaciones, 21(1-2), 159-176
Salanova, M., Peiró, J. M., \& Schaufeli, W. B. (2002). Selfefficacy specificity and burnout among information technology workers: an extension of the job demand-control model. European Journal on Work and Organizational Psychology, 11, 1-25.

Stevens, M., \& Higgins D.J. (2002). The influence of risk and protective factors on burnout experienced by those who work with maltreated children. Child Abuse Review, 11, 313-331.

Tesluk, P. E., \& Mathieu, J. E. (1999). Overcoming roadblocks to effectiveness incorporating management of performance barriers into models of work group effectiveness. Journal of Applied Psychology, 84, 200-217.

Woods, P. (1999). Intensification and Stress in Teaching. In Ronald Vandenberghe and A. Michael Huberman (Eds.), Understanding and Preventing Teacher Burnout (pp. 115138). Cambridge, MA: Cambridge University Press.

Received April 7, 2009

Revision received February 4, 2010

Accepted February 12, 2010 


\section{APPENDIX}

\section{FIGURE CAPTIONS}

Multilevel teacher stressor scale (6 Dimensions. 31 items)

Request to teachers: "Indicate the elements that interfere with or hinder the achievement of learning objectives with your students".

F1. Student misbehaviour and demotivation (Classroom level)

----- 1. The students' "couldn't-care-less" attitude.

----- 2. Student pressure on teachers

----- 3. Students' demotivation.

----- 4. Students' lack of interest.

----- 5. Students' idleness.

----- 6. Students not getting involved.

----- 7. Students' lack of discipline.

F2. Lack of decision-making (School level)

----- 8. The impositions of my superiors (Headmaster. Head of Department. Inspections. etc.).

----- 9. The organisational inflexibility of the institution and departments.

----- 10. The lack of definition of the institution's educational policy.

----- 11. The fact that it is not possible to take part in decision making (Department. Institution. etc.).

----- 12. The lack of autonomy to make my own decisions.

F3. Ambiguity of demands from Administration (Administration level)

----- 13. The ambiguity of the Administration's educational policy.

----- 14. The indifference on the Administration's part to school-related problems.

----- 15. The lack of definition of the Administration's educational policy.

----- 16. The contradictory demands we receive from the Administration.

----- 17. The frequent changes to the study curriculum.

----- 18. The frequent legal changes concerning educational matters.

F4. Student diversity (Classroom level)

---- 19. The diversity in student's paces of learning.

----- 20. The diversity in the levels of students' knowledge.

----- 21. The cultural and racial diversity among students.

----- 22. The diversity of students' learning styles.

----- 23. Students' heterogeneity in class.

F5. Workload (Classroom level)

----- 24. Lack of time.

----- 25. Work overload.

----- 26. Excessive academic load.

----- 27. Difficulty to combine teaching with other roles or tasks expected of you.

F6. Parents' insufficient involvement (Parents' level)

----- 28. Parents' collaboration is insufficient.

----- 29. Parents are not involved enough.

----- 30. Pressure from parents.

------ 31. Parents are not informed enough. 